\title{
On the Explanatory Power of Chaos Theory to Intercultural Communication
}

\author{
Zhiyuan Li \\ College of Foreign Languages \\ Northeast Dianli University \\ Jilin, China
}

\begin{abstract}
The features such as nonlinearity, instability and uncertainty etc. of chaos theory show a great relevance to the study of intercultural communication. Therefore, analyzing intercultural communication under the guidance of chaos theory not only shed light on communication barriers, language change, cultural difference and so on but also provide a new perspective of studying intercultural communication.
\end{abstract}

Keywords-chaos; chaos theory; system; intercultural communication

\section{INTRODUCTION}

Intercultural communication as an independent interdiscipline has passed a history of more than half a century since its birth in the 1950s' United States. During this period, researchers constantly taking in the results of various social sciences such as anthropology, linguistics and culturology etc. to analyze cultural cases and construct its own theory. However, due to the wide research range and scholars' different academic backgrounds, the perspective and paradigm of each theory varies a lot. Reviewing the previous literature, we can find out that most studies concentrate on the concrete situations and cases in different intercultural context whereas there is little research available on the macro-analysis of the dynamic process of intercultural communication. This paper aims to fill in this gap by employing chaos theory thus providing a new insight into the research of intercultural communication.

\section{AN OVERVIEW OF INTERCULT URAL COMMUNICAITON}

The publication of Edward T. Hall's The Silent Language in 1959 marked the birth of intercultural communication as an independent discipline. Since then, more and more scholars with various academic backgrounds have been joining the line of intercultural communication and expand its research range into comparison and contrast of language facts, cultural cognition and communication theory construction.

Reviewing the theories of intercultural communication, we find out that since its beginning in the 1970s, a lot of theories such as cultural value theory, intercultural accommodation theory etc., have been emerging. William Gudykunst (2004) in his book Theorizing Intercultural Communication summarized 17 different kinds of major intercultural communication theories [1]. Generally, these theories could be put into the following 3 categories: one belongs to Positivism based on experience and massive observation; the second category insists a comprehensive view absorbing the research findings of other adjacent subjects and the third one advocates the core value of general communication [2].

As for the research approaches, there are also various ones which can be broadly divided into the following 3 groups: the social science or functionalist approach, the interpretive approach and the critical approach. These approaches based on different fundamental as sumptions about human nature, human behavior, and the nature of knowledge [3]. The social science approach believes the predictability of culture. Researchers taking this approach usually gather the quantitative data by questionnaires or observe the firsthand subjects of the influence of culture to values and communication behaviors. However, due to the complex nature of culture and communication, researchers gradually find out that they can not identify all the variables with this approach; therefore, they gradually abandon this approach and begin to adopt the interpretive approach using a qualitative method. Scholars holding this method try to study the communication behavior from within. That is to say, they intimately involve themselves in the research and become friends with the subjects. The critical approach is somehow similar to the interpretive approach but lay more emphasis on the influence of macro-context in the communication. Summarizing the above three approaches, we can find out that they all have their own advantages and reveal the different aspects of intercultural communication. However, due to their different emphasis, they can not give a complete explanation to intercultural communication. As a result, the dialectical approach, synthesizing the advantages of the above three approaches, is proposed. Martin and Nakayama (2009) say that the dialectical approach emphasizes the processual, relational, and contradictory nature of intercultural co mmunication, which encompasses many different kinds of intercultural knowledge [3].

Through the analysis of intercultural communication theories and research approaches, we can find that the domain and the content of intercultural communication are very extensive, and the process is not a simple, certain and linear process, but a nonlinear complex system with variation and randomness. Intercultural communication is not a simple combination of language and cultural knowledge, but is affected by the communicative context, cognitive level and 
cultural background. It can be said that intercultural communication is a dynamic, nonlinear and complex process which shares many similarities with the chaotic phenomena in the physics research.

\section{APPLICATION OF CHAOS THEORY IN THE RESEARCH OF INTERCULTURAL COMMUNICATION}

\section{A. Chaos Theory}

Chaos refers to a natural state of the reality system and a kind of uncertainty. Apparently, it seems to contain a multitude of things and chaotic random, but inherently contains a rich variety of rules and orders [4]. That is to say, chaos is the uncertain and unpredictable random phenomenon of the certain, macro and nonlinear systems under certain conditions. It is an integration of the certainty and uncertainty, regularity and irregularity, order and disorder [5].

Actually, the description of chaos can be traced back to the ancient times. However, modern chaos theory was not founded until the 1960s-70s. It can be said that the finding and establishment of modern chaos theory, similar to the theory of relativity and quantum theory, is a major breakthrough to the Newtonian classical theory. Since its birth, chaos theory has attracted a lot of attention and is widely used in many disciplines such as economics and psychology. In China, researchers have started their attempts of applying chaos theory into the study of language and culture. One of the most famous representatives is Professor Zhang Gongjin and his work Cultural Linguistics. Chaos theory holds that system has the fundamental characteristics of sensitivity to initial conditions, dialectical unity of linearity and nonlinearity and the blending of order and disorder etc.. In the following section, we will make a detailed discussion of these features in intercultural communication.

\section{B. "Butterfly Effect" and Intercultural Communication}

The famous American meteorologist Lorenz proposes that sensitivity to in itial conditions is the essence of chaos theory and this is the famous "Butterfly Effect" theory. Therefore the "Butterfly Effect" is also called "sensitivity to the initial condition". It refers to the change in the initial condition of the system's long-term behavior in the process of motion will continue to expand, resulting in a huge deviation of the track so that the relative distance in space will be more and more distant [6]. That is to say, s mall changes in in itial conditions can have a huge impact on the performance of the system in the future.

Intercultural communication is such a process of extreme sensitivity to the initial condition. It involves many factors such as culture, communication and participants. Small changes in any aspect may cause huge changes in the system. From the cultural point of view, Jia Yuxin points out that all aspects of the culture involved are interrelated and interacted; culture is a very complex system [7]. Hall further points out that if you touch one side of the culture, other aspects will be affected [8]. It can be said that any subtle difference in culture can lead to a huge change in other areas and even the whole cultural system.
Take "snow" as an example, for people living in Hawaii, the word "snow" can fully represent the concept and express their ideas. But for the Eskimos in northern Greenland, "snow" is far from enough, because they need to describe different state of snow, therefore, in the Eskimo language, the descriptive words for snow are Qana (the whereabouts of snow), Qimuqsuq (the wind Piaofei snow), Perksertok (drift of snow) and so on. It is not surprising that they there is no word for "snow" in the language of equator countries because there is no need for them to describe snow. Therefore, we can see that the people living on earth may experience changes in its language, culture, thinking and so on just due to geographical differences. If this aspect is ignored, it may directly affect the smooth progress of intercultural co mmun ication.

Similarly, in the same mainstream culture, we can find many examples of "Butterfly Effect". In recent years, the study of intercultural communication is not only confined to the mainstream culture of a country, the more micro cultural groups and their communication behaviors have become a new trend of research. For example, a language may have a lot of variants due to users' different occupations, ages and social status. And this is also the case of the communication between the disabled people and nondisabled people. The disabled although share the same language and culture with the mainstream but form a subculture within because of their changes in psychological, linguistic and nonverbal aspects caused by their physical conditions. Therefore, in the process of communication, nondisabled people must take these factors into consideration to have equal and effective intercultural communication with the disabled group. These examples are typical embodiment of the "sensitivity to initial conditions" in the intercultural communication.

\section{C. "Linearity, Nonlinearity" and Intercultural Communication}

Linearity is a concept that is often mentioned in classical science. It believes that a certain reason is bound to lead to a result. Therefore, if we know the reason, then we must be able to predict the outcome. In addition, in the linear system, the whole is often from the superposition of the parts. Contrary to linearity is nonlinearity which is considered that there is no direct relationship between the two variables. The nonlinear system is not similar to linear system in the aspect of superposition which means the whole is not equal to the superposition of the parts.

Intercultural communication is a cross-progressive process of linearity and nonlinearity. It is a process of interaction between the communicators and the cultures. When a communicator contacts a new culture or a new communication group, his/her understanding of the original cultural and communicative knowledge will be challenged. Then he/she needs to adjust his/her internal structure (prior knowledge) to adapt to the new and changed environment.

Take the English language communication as an example, in the process of using the English language, a very common phenomenon is the use of a large number of idioms. English idioms are a complex system of linearity and nonlinearity. Some id ioms have the meanings equal to the superposition of 
different parts such as "a stone with two birds". Such idioms are easy to understand and are not barriers to intercultural communication. But more often, idioms are presented in the nonlinear fashion. This part is the obstacle in intercultural communication. For instance, "be taken aback" orig inally used in navigation means "to feel surprised" by extension. The mean ing of this idiom is the not the superposition of each part.

In addition, linear and nonlinear phenomena are more obvious in the process of communication between people from high and low context communication environment. High/low context is a cultural dimension proposed by Hall. High context (such as China, Italy, and Spain etc.) refers to the fact that communication information depends, to a large extent, on the social and cultural environ ment or specific contexts; the code itself is relatively weak in load of information. The communicative meaning is not a simple superposition of linguistic meaning. Halliday's (1978) saying very well reveals the concept of high context: meaning not only exists between the speakers, nor does exist in the environmental events or objects but exists in the interaction between people and environment. [9] The low context (such as the United States, Canada, Britain, etc.) language whereas is mainly dependent on the code itself to communicate the information. It can be seen that the low context communication environ ment reflects the linear characteristics, and the high context communication environment is the representative of the nonlinear characteristics. Therefore, if the Chinese and Americans are in the communication, they will have a completely different performance and understanding of each other.

\section{D. "Order, Disorder" and Intercultural Communication}

Order and disorder is another feature of chaos. Order is the regularity of the development and change of the system. Whereas, disorder refers to the regular change and development of systems and the internal systems are accompanied by some of the phenomenon of irregularities at the same time. The system is thus to reach a steady state with the ordered and disordered changing overlapping each other. Here involves a very important concept "attractor". The attractor is a stable state in the system, which is attractive to the surroundings, and makes the system stable. In addition to stability, the abnormal phenomenon is affected by the "strange attractor". It is under the interactive action of the attractors and the strange attractors that the system is in the state of coexistence of order and disorder.

Intercultural communication is a dialectical unity of order and disorder. Take the value in intercultural communication as an example, the values involved in the study of intercultural communication refer to a set of value systems which are accepted and held by the mainstream culture in a certain country. Although this system is invisible to the outside, it does affect all aspects of people's lives. It can be said that values are a regular and orderly part of a culture. It acts as a function of the attractor, which attracts the cultural system to stabilize and keep down in a state, and then presents its unique cultural characteristics. Some foreign scholars such as the Kluckhohns, Strodtbeck, Hofstede, and Hall and so on, based on their own research, put forward the cultural value assessment systems which we call value dimensions. These theories provide an effective reference framework for us to study different cultures and to promote effective communication. But these value dimension theories are established on the basis of the mainstream culture. In the process of intercultural communication, we should also take into account each subculture and even each person. This is we mentioned as the strange attractor. The existence of these strange attractors makes intercultural communication showing abnormal, disordered states from time to time.

From the essence of intercultural communication, we can see it is also a kind of human to human communication behavior; therefore, it is bound to be governed by the general rules of communication. But as mentioned before, language, culture and communication are very complex dynamic systems. To a certain extent, "the commun ication between any human being can be regarded as an intercultural communication." [7] In the process of intercultural communication, it is impossible to wholly follow the rules of communication. That requires intercultural communication participants to learn common rules in intercultural communication, to master certain knowledge of communication, and to understand the cultural conflicts and adaptation in intercultural environment. What is more important is that intercultural communicator should be able to deal with all kinds of emergencies under the guidance of communicative rules. That is the embodiment of good intercultural communication competence. Zhang Hongling points out, "intercultural communicative competence should not only confined to a specific cultural commun ication context, but must be able to transcend specific cultures, and flexibly applied to different communication situations. That is the essence intercultural communication competence" [10].

\section{CONCLUSION}

Through the above analysis we can see that some advocates of chaos theory and intercultural communication studies show a high correlation. From the point of view of chaos theory, intercultural communication is a nonlinear, chaotic and complex system, and the system is extremely sensitive to initial conditions. Therefore, applying research framework of chaos theory to the study of intercultural communication will bring us a lot of inspiration. First of all, intercultural communication is a dynamic process of development. In the communication, any small aspects of the changes are likely to affect the communication behaviors and the process. Secondly, in the study of intercultural communication, we can build a more macro perspective which will break the barriers of language, culture, communication and other factors. Thirdly, the introduction of chaos theory can change the methodology of intercultural communication. Intercultural communication is not a simple superposition of all parts. This puts forward a certain challenge to the traditional experimental measures in the study of humanity and social sciences. Professor Zhang Gongjin (1997) points out that the traditional linear method of linguistics is not enough; we need a new concept and method to analyze language [11]. Here we can draw a conclusion that the study 
of intercultural communication needs a new concept and a method as well.

Above, we have analyzed the basic theory and characteristics of chaos, and the application of chaos theory in intercultural communication. But this research is still in its preliminary stage; its effectiveness also remains to be further studied. It can be anticipated that the specific contexts, individual difference, interactive competence in intercultural communication may find practical and reasonable explanation with the help of chaos theory. With more and more studies in this area the scope of both intercultural communication and chaos theory will be expanded.

\section{REFERENCES}

[1] W. Hu, "Tendencies and charateristics: a review of intercultural communication research," Foreign Languages in China, vol. 3, p. 4, March 2006.
[2] Y. Jia, "Intercultural communicaiton research in America," Foreign Lauguage Research, vol. 3, p. 52, March 1992.

[3] J. N. Martin and T. K. Nakayama, Intercultural Communication in Contexts, $4^{\text {th }}$ ed., Beijing: Foreign Language Teaching and Research Press, 2009, p. 55.

[4] D. Miao and H. Liu, Studies in Chaos Theory, Beijing: Remin University of China Press, 1994, p. 14.

[5] Y. Ding, "Basic understanding of chaos theory," Modern Physics, vol. 1, p. 49, January 1996.

[6] G. Zhang and S. Ding, A Course to Cultural Linguistics, Beijing: Education Sciences Press, 2004, p. 107.

[7] Y. Jia, Intercultural Communicaiton, Shanghai: Shanghai Foreign Language Education Press, 1997, p. 19.

[8] E. T. Hall, Beyong Cultures, Garden City, N. Y.: Doubleday \& Company, 1976, pp. 85-103.

[9] M. A. K. Halliday, Language as Social Semiotic, Edward Amold, 1978.

[10] H. Zhang, Intercultural Foreign Language Teaching, Shanghai: Shanghai Foreign Language Education Press, 2007, p. 72.

[11] G. Zhang, "Chaos theory and language research," Language Teaching and Research, vol. 3, pp. 61-65, March 1997. 